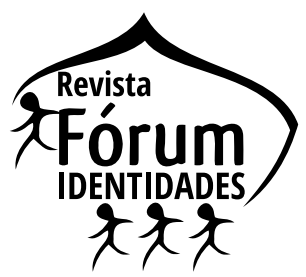

\title{
LETRAMENTO LITERÁRIO PARA SURDOS: UMA PROPOSTA DE APLICABILIDADE COM POESIA SURDA ${ }^{1}$
}

\section{LITERARY LITERACY FOR THE DEAF: A PROPOSAL OF APPLICABILITY WITH DEAF POETRY}

\author{
Taísa Aparecida Carvalho Sales ${ }^{2}$ \\ Clarice Lottermann ${ }^{3}$
}

\begin{abstract}
Resumo: Buscando oportunizar às crianças surdas esse direito que Candido considera fundamental, neste artigo temos como objetivo apresentar ao leitor o conceito de literatura surda, letramento literário e desenvolver uma proposta de letramento literário para ser aplicado em sala de aula aos alunos surdos. Consideramos, a título do estudo, alunos surdos do nono ano do ensino fundamental 2, em uma escola bilíngue, ou seja, na qual a língua de sinais é a língua de instrução. Usaremos um poema em língua de sinais, cujo título é Mudinho, do autor Edvaldo Santos, mais conhecido como Edinho poesia.
\end{abstract}

Palavras-chave: Letramento literário. Literatura Surda e poesia.

\begin{abstract}
Seeking to provide deaf children with this right that Candido considers essential, in this article we aim to introduce the reader to the concept of deaf literature, literary literacy and develop a proposal for literary literacy to be applied in the classroom to deaf students. We considered, for the purpose of this study, deaf students in the ninth grade of elementary school 2, in a bilingual school, that is, in which sign language is the language of instruction. We will use a poem in sign language, whose title is Mudinho, by the author Edvaldo Santos, better known as Edinho Poetry.
\end{abstract}

Keywords: Literary literacy. Deaf Literature and Poetry.

\footnotetext{
${ }^{1}$ Artigo recebido em 15 de agosto de 2021 e aceito para publicação em 30 de setembro de 2021.

2 Docente do Departamento de Letras: Libras e Tradução da Faculdade de Letras da Universidade Federal de Goiás - UFG. Doutoranda no Programa de Pós-Graduação em Letras, na área de concentração Linguagem e Sociedade, na linha de pesquisa: Literatura, memória, cultura e ensino da Universidade Estadual do Oeste do Paraná - Unioeste (2021-2025). Membra do Grupo de Pesquisa Poéticas do Imaginário e Memória na Universidade Estadual do Oeste do Paraná - UNIOESTE/Campus de Cascavel. Membra do grupo de pesquisa Literatura em Estudos Transdisciplinares e Residuais, da Universidade Federal do Amazonas - UFAM. Membra do grupo de pesquisa Relações de gênero, poder e violência em literaturas de língua portuguesa - UFAM carvalhotaisa@yahoo.com.br e taisasales@ufg.br ORCID: http://orcid.org/0000-0001-8695-3600.

${ }^{3}$ Professora Sênior da Universidade Estadual do Oeste do Paraná- Unioeste, atua no Programa de Pós-Graduação em Letras. Doutora em Estudos literários pela Universidade Federal do Paraná - UFPR. Membro do grupo de pesquisa Confluências da Ficção, História e Memória na Literatura e nas Diversas Linguagens e do GT Leitura e Literatura Infantil e Juvenil, da ANPOLL. clalottermann@hotmail.com. ORCID: https://orcid.org/0000-0002-6184-8297.
} 


\section{Introdução}

A literatura é fundamental nas mudanças sociais, na evolução do comportamento humano e na construção da identidade cultural. Um ensino da literatura que se fundamente na leitura e resulte em uma prática dialógica seria o modelo ideal de educação a ser ofertada para nossas crianças. Esse ideal de ensino levaria a criança a abrir seus horizontes uma vez que, a partir de sua própria experiência de leitura, agiria sobre sua comunidade, teria condições para pensar sobre os fatos ocorridos ao seu redor, seria capaz de expor opiniões e buscar direitos. Pensaria criticamente a respeito de assuntos polêmicos, tornando-se uma pessoa humanizada, um cidadão em busca de direitos.

Entretanto, os surdos, enquanto crianças, não têm acesso aos primeiros contatos - como os ouvintes têm com as cantigas de rodas, as parlendas, os contos de fadas contados e cantados por pais, avós, tios, antes mesmo da professora na escola. Ao contrário, os surdos passam a ter contato com esse mundo literário a partir do momento em que adquirem a língua de sinais na escola. Essa situação acontece, em muitos casos, porque as famílias não sabem ou pouco sabem a língua de sinais ou alguma outra forma de apresentar a literatura ao seu filho surdo.

Buscando oportunizar às crianças surdas esse direito que Candido reflete fundamental, neste artigo temos como objetivo apresentar ao leitor o conceito de literatura surda, letramento literário e desenvolver uma proposta de letramento literário para ser aplicado em sala de aula aos alunos surdos. Consideramos a título do estudo alunos surdos do nono ano do ensino fundamental 2, de uma escola bilíngue, ou seja, na qual a língua de sinais é a língua de instrução. Usaremos um poema em língua de sinais, cujo título é Mudinho, do autor Edvaldo Santos, mais conhecido como Edinho poesia.

\section{Literatura surda}

Os surdos instituem uma comunidade linguística que foi reconhecida no Brasil pela Lei $n^{\circ}$ 10.436/2002. Por meio do reconhecimento da Língua Brasileira de Sinais, houve várias publicações dessa comunidade. Por volta dos anos 90, surgiram as primeiras obras. Esse conjunto de obras é denominado como literatura surda.

Esta apresenta as vivências, narrações de histórias e piadas que traduzem a cultura do povo surdo, sendo difundidas e transmitidas de geração em geração por meio da língua de sinais. Para Karnopp (2010), essa forma de expressão permite

a produção de textos literários em sinais, que traduz a experiência visual, que entende a surdez como presença de algo e não como 
falta, que possibilita outras representações de surdos e que considera as pessoas surdas como um grupo linguístico e cultural diferente. (KARNOPP, 2010, p. 161)

As principais maneiras de realização da literatura surda são: criação, tradução e adaptação. Nesse sentido, as traduções são realizadas, geralmente, da língua portuguesa para a língua de sinais. Recorre-se a alguns clássicos da literatura existentes em línguas na modalidade escrita e faz-se a tradução para a língua de sinais para ser disponibilizado em mídias visuais. A Editora Arara-Azul é maior responsável por esse trabalho no Brasil.

No tocante à adaptação, é realizada uma espécie de transposição de uma obra literária para outro contexto literário. Ao realizar essa transposição, os "pontos de vista" são alterados e dá-se início a uma nova construção de sentidos para um texto pré-existente. Dessa maneira, retoma-se o antigo para construção de novo, diversificando olhares frente a obra, trazendo novas linguagens a favor da literatura. As obras consideradas criação são textos originais, geralmente de autores surdos, que surgem como forma de relatar suas vivências e condição de ser surdo. Além de textos em prosa, cuja tradição em meio às comunidades surdas é grande, a poesia também assume protagonismo, em especial no fim dos anos 90, conforme esclarece Sutton-Spence (2021):

As comunidades surdas têm uma longa tradição de narrativa em prosa, mas os textos que hoje chamamos de poemas só passaram a existir nos anos 70 ou 80 do século XX nos EUA (ROSE, 1992). A tradição de poesia em Libras é nova e provavelmente começou apenas no final dos anos 90. Porém, não importa que essa tradição seja recente no Brasil. A poesia em Libras está se espalhando e se desenvolvendo cada vez mais para se tornar um gênero literário importante no mundo (SUTTON-SPENCER, 2021, p. 133).

Para os estudiosos da área, os poemas em língua de sinais expressam e refletem a identidade surda da comunidade. Essa poesia é uma forma de arte com regras e padrões próprios. Para reconhecer um poema em língua de sinais e diferenciá-lo de uma prosa, deve-se observar alguns pontos importantes, como o fato de os poemas em língua de sinais serem, de certa forma, mais "organizados" que as histórias. As regras são de grande importância, sendo escolhidas pelo próprio autor e/ou em tradições literárias. Existem algumas classificações dentro do gênero poesia: traduções, poemas homenagens, poemas malucos, apresentação do poema, poemas líricos, poemas narrativos dramáticos e épicos. Há também a categoria de poemas adaptados de outros gêneros como o Haicai, o Renga e o Duetos, Pelejas ou batalhas poéticas. 
$\mathrm{Na}$ poesia em Libras, os artistas apresentam novas ideias de novas maneiras usando formas originais da língua. $O$ foco está na linguagem estética que, geralmente, é fortemente visual e cuidadosamente construída para maximizar o impacto dos sentidos. A forma é na maioria das vezes curta, raramente composta por mais de três minutos e normalmente com cerca de dois minutos. É visualmente muito intensa e muitas vezes o seu significado não é muito claro, de modo que o público precise se esforçar, pensar sobre a forma da linguagem para entender o significado (SUTTON-SPENCER, 2021, p. 78).

\section{A representação da poesia surda nas batalhas de poesias autorais}

Quando se fala em batalhas de poesias autorais, ou os slam, comumente conhecidos pelos ouvintes, torna-se importante entender suas regras e seu funcionamento. D’alva (2011) estabelece que é difícil uma definição exata da experiência.

Poderíamos definir o poetry slam, ou simplesmente slam, de diversas maneiras: uma competição de poesia falada, um espaço para livre expressão poética, uma ágora onde questões da atualidade são debatidas, ou até mesmo mais uma forma de entretenimento. De fato, é difícil defini-lo de maneira tão simplificada, pois, em seus 25 anos de existência, o poetry slam se tornou, além de um acontecimento poético, um movimento social, cultural, artístico que se expande progressivamente e é celebrado em comunidades em todo o mundo. (D’ALVA, 2011, p. 120)

Criado por Marc Kelly Smith na década de 80, os Slam Poetry, apresentam-se como uma modalidade de representação performática da poesia. Com o tempo, recebeu influência do Hip Hop, abrindo espaço para temáticas como racismo, machismo, desigualdades sociais e LGBTQIAfobias. O Slam tem um caráter competitivo: um poeta se apresenta e um grupo de jurados o avalia de 0 a 10, em uma espécie de confronto indireto. No Brasil, uma das principais responsáveis pela difusão é a slammer Roberta Estrela D’alva e também criadora do ZAP (Zona Autônoma da Palavra).

O Slam do Corpo, criado pelo Corpo Sinalizante, é o primeiro grupo no Brasil que reúne poetas surdos e ouvintes em uma performance que envolve língua portuguesa e língua brasileira de sinais.

De acordo com Santos,

Neste Slam ocorrem dois momentos chamados: Corpo Aberto e Batalha. No primeiro, o microfone é aberto para qualquer pessoa apresentar uma poesia livremente e em qualquer língua. No segundo, ocorre a competição de poesias. As regras que compõe o Slam do Corpo são as mesmas estabelecidas em outros Slams: as poesias devem ser autorais, ter duração máxima de 3 minutos e não devem ser utilizados figurinos e adereços, cenários. Nas batalhas 
são formadas duplas de surdos e ouvintes, que apresentam poesias autorais com temática livre e os jurados são escolhidos minutos antes das apresentações, composto por pessoas surdas e ouvintes da plateia que dão notas de 0 a 10 . Os vencedores na maioria das vezes recebem livros e prêmios educativos. (SANTOS, 2018, p. 03)

É o corpo em movimento que envolve a poesia surda presente no Slam, repleto de sentidos, por meio dos gestos, expressões, e a Libras se amplia enquanto língua, provocando no público leitor uma sensação antes desconhecida. Outra característica a ser considerada na poesia surda é a forma como ela se constitui. De acordo com Segala (2016 apud MOURÃO (ano e página) "a rima, que para os ouvintes se realiza a partir da sonoridade, no caso dos surdos, é construída com as configurações de mão, que obviamente não ocorre na literatura em português. São equivalências."

\title{
A poesia surda enquanto resistência
}

Pensar em poesia surda e que se expressa por meio das mãos, do corpo, também é pensar na resistência da comunidade surda, em sua luta pelo empoderamento linguístico e identitário, pois

\begin{abstract}
A literatura de um povo é o desenvolvimento do que ele tem de mais sublime nas ideias, de mais filosófico no pensamento, de mais heroico na moral e de mais belo na natureza; é o quadro animado de suas virtudes e de suas paixões, o despertador de sua glória e o reflexo progressivo de sua inteligência. E, quando esse povo, ou essa geração, desaparece da superfície da terra, com todas as suas instituições, crenças e costumes, escapa a literatura aos rigores do tempo para anunciar às gerações futuras qual fora o caráter e a importância do povo, do qual é ela o único representante na posteridade. Sua voz, como um eco imortal, repercute por toda parte, e diz: em tal época, debaixo de tal constelação e sobre tal ponto do globo existia um povo cuja glória só eu a conservo, cujos heróis só eu conheço. Vós, porém, se pretendeis também conhecê-lo, consultai-me, porque eu sou o espírito desse povo e uma sombra viva do que ele foi. (MAGALHÂES, 1836, p. 1)
\end{abstract}

O slammer Edinho dos Santos é um dos maiores representantes da poesia surda. O poeta aborda em suas poesias temas como racismo e preconceitos em relação ao negro e ao surdo. Apresentamos um trecho da poesia Negro surdo em que faz parceria com o artista ouvinte James Bantu. 
Figura 1 - Edinho interpreta a poesia "Negro surdo"

EDINHO INTERPRETA POESIA "NEGRO SURDO”

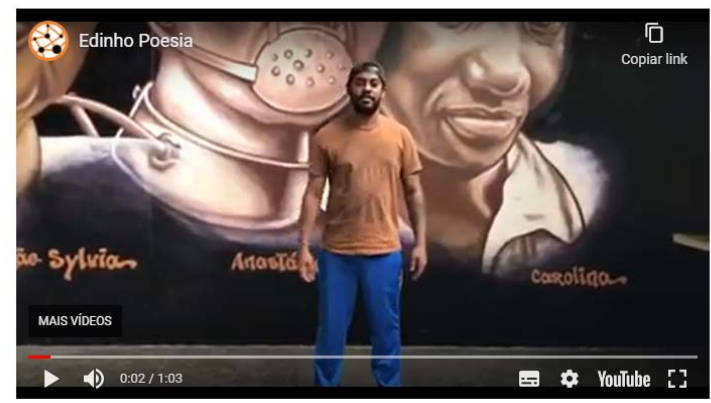

Fonte: https://www.agenciamural.org.br/surdo-de-nascenca-edinho-faz-poesia-com-a-lingua-de-sinais/

Transcrição para a língua portuguesa de um trecho:

\author{
"Vocês conhecem poesia? \\ Eu trago poesia de periferia \\ Poesia de favela Identidade negro-surdo \\ A cidade me alveja com seus sons \\ Com suas luzes, suas faíscas \\ São como estrelas caídas no chão (...)”
}

A poesia surge como um espaço de reflexão sobre as vivências, as experiências e as identidades que podem ser individuais ou coletivas. A partir da poesia Mudinho, do mesmo poeta, é que traremos a proposta no item 3.

\title{
Letramento literário
}

O letramento literário significa, em linhas gerais, um conjunto de práticas e eventos sociais que envolvem a interação leitor e escritor, produzindo o exercício socializado na escola por meio da leitura de textos literários, sejam esses canônicos ou não, de acordo com Cosson (2009). Assim, a finalidade principal é a construção e reconstrução dos significados em relação ao texto literário lido dentro ou fora da sala de aula.

Para Street (2014), esse modelo de letramento - em que a cultura, a família e a sociedade contribuem - torna evidente as relações de poder e os contrastes sociais porque, ao entrar em contato com uma obra, o sujeito é capaz de construir e reconstruir sentidos, compreendendo e significando sua prática.

Cosson (2016) explica que há dois extremos:

As atividades que envolvem literatura oscilam entre dois extremos: a exigência de domínio de informações sobre a literatura e o imperativo de que o importante é que o aluno leia, não im- 
portando bem o que, pois a leitura é uma viagem, ou seja, mera fruição. No ensino fundamental, predominam as interpretações de texto trazidas pelo livro didático, usualmente feitas a partir de textos incompletos, e as atividades extraclasses, constituídas de resumos dos textos, fichas de leitura, e debates em sala de aula, cujo maior objetivo é recontar a história lida ou dizer o poema com suas próprias palavras (COSSON, 2016, p. 22).

O texto literário não deve ser observado simplesmente como uma estrutura textual, pois sinaliza para a construção de novos caminhos sobre a interpretação de um mundo vivenciado por ambos - escritor e leitor - protagonistas envolvidos no processo de aprendizagem. Para Cosson (2016), o processo de letramento literário deve envolver aspectos que conciliem os diversos textos literários que circulam nas esferas sociais. Segundo o autor,

Devemos compreender que o letramento literário é uma prática social e, como tal, responsabilidade da escola. A questão a ser enfrentada não é se a escola deve ou não escolarizar a literatura, como bem nos alerta Magda Soares, mas sim como fazer essa escolarização sem descaracterizá-la, sem transformá-la em um simulacro de si mesma que mais nega do que confirma seu poder de humanização (COSSON, 2016, p. 23).

Cosson (2016) propõe duas sequências: uma básica e outra expandida. Essas sequências procuram sistematizar a abordagem do material literário em sala de aula integrando, fundamentalmente, três perspectivas metodológicas, às quais podemos correlacionar à literatura surda: (i) a técnica da oficina, que consiste em levar o aluno a construir pela prática seu conhecimento; (ii) a técnica do andaime, que parte do princípio de que cabe ao professor de literatura surda sustentar as atividades a serem desenvolvidas de maneira autônoma pelos alunos surdos, relacionando a atividade de reconstrução do saber literário, que envolve a pesquisa e desenvolvimento de projetos por parte desses alunos; e, (iii) o portfólio, que oferece ao aluno surdo e ao professor de literatura surda a possibilidade de registrar as atividades realizadas ao mesmo tempo em que permite visualizar o crescimento alcançado pela comparação dos resultados.

Dessa forma, a sequência básica é constituída por quatro passos: motivação, introdução, leitura e interpretação. A sequência expandida tem as mesmas etapas que a sequência básica, porém, na expandida há dois momentos de interpretação. O primeiro refere-se à compreensão global dos textos, incluindo alguns aspectos formais, e o segundo é o aprofundamento de um dos aspectos do texto que seja mais pertinente para os propósitos do professor.

Assegurar que esse tipo de conhecimento chegue aos surdos é um jeito de efetivar um compromisso ético evidente, pois torna possível ao surdo 
não apenas aprimorar sua competência leitora, mas também apropriar-se do seu direito à literatura.

\section{Aplicabilidade da sequência básica no poema Mudinho, do poeta surdo Edinho}

Como proposta de aplicação do método apresentado por Cosson (2016), vamos pensar em alunos surdos do nono ano do ensino fundamental 2, com idade variante de 14 a 20 anos, em uma escola bilíngue, considerando de que o professor já tenha trabalhado sobre os gêneros literários dentro da literatura surda.

Usaremos a sequência básica para a nossa proposta, perpassando pelos quatro passos: motivação, introdução, leitura e interpretação.

A motivação consiste na preparação do aluno para que ele "entre" no texto. O professor de literatura surda atuará de forma lúdica, com uma temática relacionada ao texto literário que será lido e tem como objetivo principal incitar a leitura proposta. Para isto trouxemos como exemplo o vídeo Os surdos tem voz, de Leonardo Castilho - Cabine 11.

Figura 2 - Os surdos têm voz, de Leonardo Castilho

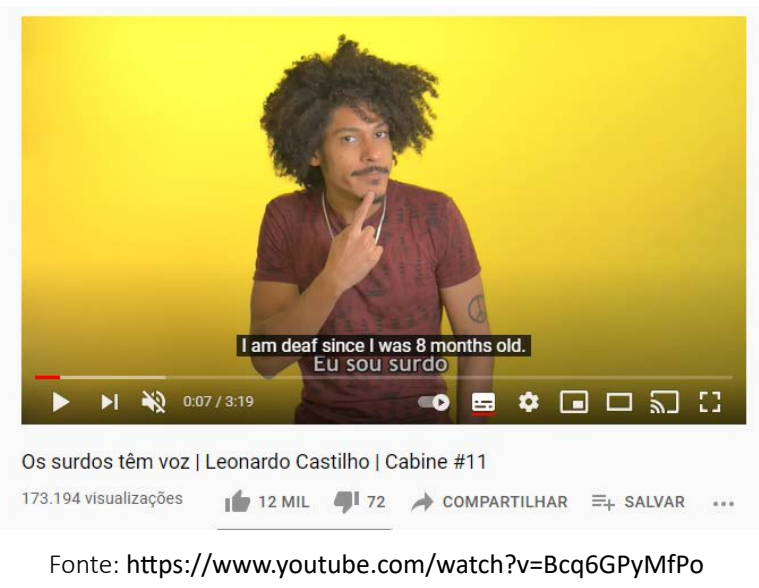

$\mathrm{O}$ vídeo tem como tema o preconceito em relação às pessoas surdas: por que são chamadas de mudas se têm voz? Por que são vistas como "quase" perfeitas e por que muitos ouvintes se surpreendem quando os surdos fazem coisas que são totalmente normais? A priori, o professor deve fazer uma breve discussão em Libras sobre esses questionamentos.

Conforme Lima (2014), a aquisição dos conhecimentos em Libras pelas crianças surdas, sendo utilizada como base de instrução de ensino, é um dos fatores essenciais para garantir uma aquisição plena da leitura e escrita do português como segunda língua pela criança surda. 
No próximo passo da sequência, ou seja, na introdução, o professor faz a apresentação do autor e da obra. Nesse momento, o professor apresentará em Libras quem é Edinho e a sua poesia Mudinho. O professor pode fazer o uso de material de apresentação - como powerpoint, vídeos curtos - com as devidas informações a respeito do autor e da obra. Perlin e Miranda (2003) consideram que a experiência visual é importante, pois significa a utilização da visão como meio de comunicação:

Experiência visual significa a utilização da visão, em (substitui total a audição), como meio de comunicação. Desta experiência visual surge a cultura surda representada pela língua de sinais, pelo modo diferente de ser, de se expressar, de conhecer o mundo, de entrar nas artes, no conhecimento cientifico e acadêmico. A cultura surda comporta a língua de sinais, a necessidade do intérprete, de tecnologia de leitura (Perlin e Miranda, 2003, p. 218).

Figura 3 - Poeta Edvaldo Santos

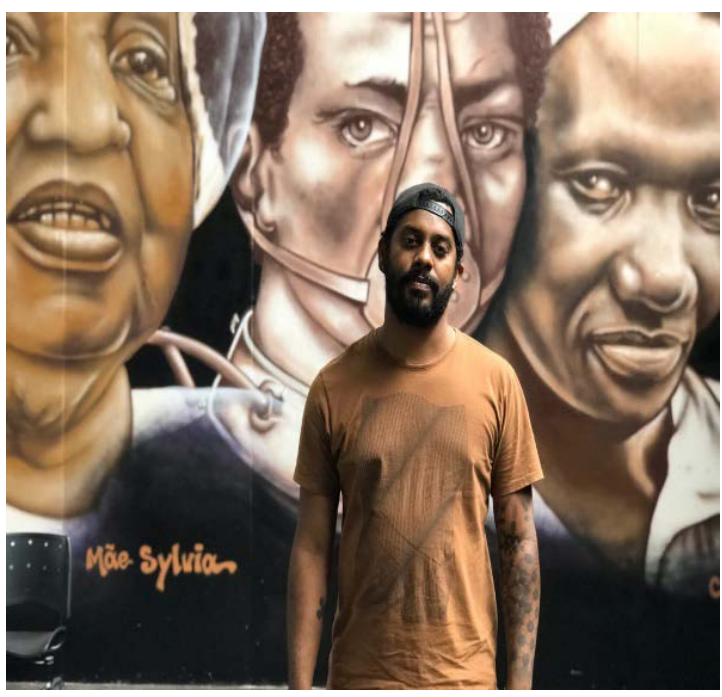

O olhar expressivo e as mãos ágeis de Edvaldo Santos, 33, explodem na poesia - quase autobiográfica - sobre ser um homem negro, surdo e periférico. 0 paulistano encontrou na Libras (Língua Brasileira de Sinais), uma maneira de comunicar as inquietações observadas desde muito cedo.

Fonte: https://www.agenciamural.org.br/surdo-de-nascenca-edinho-faz-poesia-com-a-lingua-de-sinais/

A terceira etapa, leitura do texto em si mesmo, deve ter o acompanhamento do professor de literatura surda. $\mathrm{O}$ autor chama esse acompanhamento de "intervalos", no qual há a possibilidade de aferição da leitura, assim como solução de algumas dificuldades relacionadas à compreensão de vocabulário ou mesmo de partes do texto. Tal sugestão é de fundamental importância para que o aluno não perca o interesse ao longo da leitura. 
Figura 4 - imagens do poema em Libras

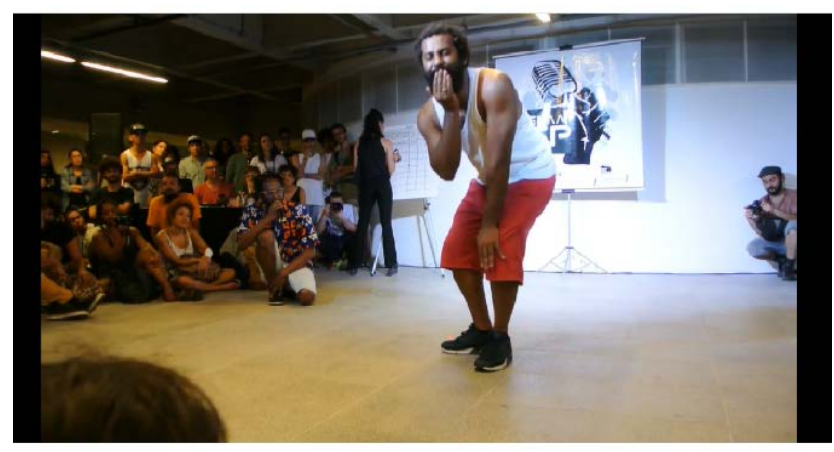

Fonte: https://vimeo.com/242497402

Transcrição do poema a ser trabalhado para língua portuguesa:

\footnotetext{
“Quando eu era pequeno/ diziam: 'mudinho, mudinho, mudinho'/ Eu já homem feito e barbado/ e eles: 'mudinho, mudinho, mudinho/ Me casei, tive filho/ e eles: 'mudinho, mudinho, mudinho/ Eu envelheci, me cansei, me curvei/ e eles: 'mudinho, mudinho, mudinho/ Mudinho? Não, meu nome é Edinho, porra".
}

Para essa etapa, o professor apresenta a poesia em vídeo, sem qualquer interrupção. Depois, passa novamente e vai parando e perguntando aos alunos se entenderam os sinais em libras e o significado das frases, das metáforas, das analogias, fazendo assim esse acompanhamento. Ao final, passa o vídeo completo novamente.

A última etapa, a interpretação, para Cosson (2016) se dá em dois momentos, um interior e outro exterior. O momento interior compreende a decifração, é chamado de "encontro do leitor com a obra", momento chave podemos chamar assim, pois é quando o aluno tem a compreensão daquilo que leu e é por isso que não pode ser de forma alguma substituída por algum tipo de intermediação como resumo do livro, filmes, minisséries, estas outras artes podem ser complementos. Essa etapa será o momento em que o aluno surdo compreende o que o poema diz, reflete sobre isso. Já o momento exterior é a "materialização da interpretação como ato de construção de sentido em uma determinada comunidade" (COSSON, 2016, p. 65). Assim, o aluno surdo consegue expressar-se e dialogar com seus colegas sobre a compreensão obtida por meio do poema. Podemos colocar alguns exemplos de ponderamentos a serem propostos: Como identificamos um poema em Língua de sinais? De que tema ou quais temas o poema trata? Como o "eu poético" apresenta suas emoções? Você já passou por alguma situação de preconceito e anulação de identidade como apresenta o poema? 


\section{Considerações finais}

Dessa forma, o letramento literário contribui no processo de desenvolvimento de uma prática social crítica, reflexiva e transformadora. A compreensão de Cosson (2016) em relação à literatura nos remete aos críticos literários Compagnon (2010), Todorov (2009) e ao próprio Sartre (2004), visto que, para esses autores, a leitura literária exige uma postura ativa do leitor. Conforme Cosson (2016, p. 17), "a experiência literária não só nos permite saber da vida por meio da experiência do outro, como também vivenciar essa experiência”. Ao compreendermos e aplicar as quatro etapas propostas por Cosson (2016).

Ao considerarmos o ensino da literatura que se fundamente na leitura e resulte em uma prática dialógica como o modelo ideal de educação a ser ofertada para nossas crianças, podemos observar que essa proposta de letramento literário para surdos pode proporcionar esse ideal de ensino, levando o aluno surdo a abrir seus horizontes, uma vez que, a partir de sua própria experiência de leitura, agiria sobre sua comunidade, teria condições para pensar sobre os fatos ocorridos ao seu redor, seria capaz de expor opiniões e buscar seus direitos.

\section{Referências}

BATISTA, Guilherme Martins. O que é o slam do corpo?. 2017. (2 min. 54s). Disponível em: https://www.youtube.com/watch?v=yjp1TWEl0q0.

COMPAGNON, Antoine. O demônio da teoria: literatura e senso comum. Tradução de Cleonice Paes Barreto Mourão e Consuelo Fortes Santiago. 2. ed. Belo Horizonte: UFMG, 2010.

COMPAGNON, Antoine. Literatura para quê? Tradução de Laura Taddei Brandini. Belo Horizonte: UFMG, 2009.

COSSON, Rildo. Letramento literário teoria e prática. 2. ed. São Paulo: Contexto, 2016.

COUTO, Cléber. Casal feliz. Ilustrações: Cleber Couto. Belém-Pará, 2010.

D’ALVA, Roberta Estrela. Um microfone na mão e uma ideia na cabeça - o poetry slam entra em cena. In: Synergies Brèsil. n. 9. 2011. Pg. 119-126.

ESPÍNDOLA, Amarildo João; PISSINATTI, Larissa Gotti; SILVA, Elielza Reis da. Curupira surdo. Ilustrações: Suzana Souza Frota Alcântara e Leila Silva de Sena. Porto Velho: AICSA, 2016.

HESSEL, Carolina; KARNOPP, Lodenir; ROSA, Fabiano. Rapunzel surda. Ilustrações: Carolina Hessel. Canoas: ULBRA, 2003a. 
HESSEL, Carolina; KARNOPP, Lodenir; ROSA, Fabiano. Cinderela surda. Ilustrações: Carolina Hessel. Canoas: ULBRAS, 2003b.

KARNOPP, Lodenir Becker. Produções culturais dos Surdos: análise da literatura surda. In: Cadernos de Educação. Pelotas, maio/agosto 2010, p. 144-177. Disponível em: https://periodicos.ufpel.edu.br/ojs2/index.php/caduc/article/view/1605/1488. Acesso em: 10 jul. 2020.

KARNOPP, Lodenir Becker. Literatura Surda. In: Educação Temática Digital. v. 7, n. 2, junho/2006, p. 98-109. Disponível em: https://www.ssoar.info/ssoar/bitstream/handle/document $/ 10162 /$ ssoar-etd-2006-2-karnopp-literatura_surda.pdf?sequence $=1 \&$ isAllowed $=$ y\&lnkname $=$ ssoar-etd-2006-2-karnopp-literatura_surda.pdf. Acesso em: 10 jul. 2020.

LIMA, Marisa Dias. Libras (L1) como instrumento facilitador no processo de ensino aprendizagem da língua portuguesa (12). Disponível em: http:/ /www.ileel.ufu.br/anaisdosielp/wp-content/uploads/2014/11/824.pdf. Acesso em 10 jul. 2021.

MONTEIRO, Tayana. Negrinho e Solimões. Ilustrações: Sérgio Barbosa Lopes Júnior. Manaus: BK editora, 2014.

MOURA, Maynara Costa de Campos. Das bocas às mãos mexedeiras: marcas culturais e identitárias na literatura surda. Trabalho de conclusão de curso (TCC). Universidade do Estado da Bahia. Jacobina, BA - 2018.

MORGADO, Marta. Literatura em Língua Gestual. In: KARNOPP, Lodenir; KLEIN, Madalena; LAZZARIN, Márica Lise Lunardi (Orgs.). Cultura surda na contemporaneidade: negociações, intercorrências e provocações. Canoas: ULBRA, 2011, p. 151-171

MOURÃO, Cláudio Henrique Nunes. Literatura surda: produções culturais dos surdos em língua de sinais. In: KARNOPP, Lodenir; KLEIN, Madalena; LAZZARIN, Márica Lise Lunardi (Org.). Cultura surda na contemporaneidade: negociações, intercorrências e provocações. Canoas: ULBRA, 2011, p. 71-89.

MOURÃO, Cláudio Henrique Nunes. Literatura surda: produções culturais de surdos em língua de sinais. Porto Alegre: UFRGS, 2011. Dissertação (Programa de Pós-Graduação em Educação). Universidade Federal do Rio Grande do Sul, Porto Alegre, 2011. Disponível em: https://www.lume.ufrgs.br/handle/10183/32311. Acesso em: 10 jul.2020.

MOURÃO, Cláudio Henrique Nunes. Literatura surda: experiência das mãos literárias. Porto Alegre: UFRGS, 2016. Tese (Programa de Pós-Graduação em Educação). Universidade Federal do Rio Grande do Sul, Porto Alegre, 2016. Disponível em: https://lume. ufrgs.br/handle/10183/151708. Acesso em: 10 jul.2020

PISSINATTI, Larissa Gotti. A literatura surda na sala de aula e a formação da consciência de si. 2020. Tese. Universidade Estadual de Maringá, Maringá-PR,2020.

SANTOS, Natielly de Jesus. O Slam do Corpo e a representações da poesia surda. In: Revista de Ciências Humanas. v. 18, n. 02, jul./dez. 2018. 
SEGALA, Rimar. Tradução Intermodal e Intersemiótica/Interlingual: Português brasileiro escrito para Língua Brasileira de Sinais. 2010. Dissertação (Mestrado em Estudos da Tradução). Universidade Federal de Santa Catarina, Florianópolis-SC, 2010

STAM, Robert. Teoria e prática da adaptação: da fidelidade à intertextualidade. In: Revista Ilha do Desterro. A Journal of English Language, Literatures in English and Cultural Studies, América do Sul, 2009.

SUTTON-SPENCE, Rachel. Literatura em Libras. Editora Arara Azul, Petrópolis - RJ, 2021. 